\title{
Seventy five years of electroconvulsive therapy : a look back and the future ahead
}

\author{
Siddharth Arya ${ }^{1}$ \\ Aniruddha Basu ${ }^{2}$ \\ ${ }^{1}$ Resident Doctor, Department of Psychiatry, PGIMS, Rohtak, India. \\ ${ }^{2}$ Senior Resident (Post Doctoral Fellow), Department of Psychiatry, National Institute of Mental \\ Health and Neurosciences (NIMHANS), Bangalore, India. \\ E-mail - draniruuddhabasu@gmail.com
}

\section{ABSTRACT}

Electroconvulsive therapy has been in existence for last 75 years. Although newer pharmacological agents have been introduced during this period, ECT has continued to enjoy special status in management of certain psychiatric illnesses. This review looks at the history of ECT, indications of its use, its procedure and the controversies that arose over this period. Status of ECT according to new mental health care bill 2013 has also been discussed.

Key words : Electroconvulsive therapy, mechanism of ECT, indications of ECT..

\section{INTRODUCTION AND HISTORY}

Treatment of psychiatric illness through induction of seizures is not a new concept and was used by Paracelsus as early as sixteenth century by injecting camphor [1]. At the beginning of the $20^{\text {th }}$ century the treatment of general paresis by inducing malarial fever gave medical science a whole new principal for management treatment of one condition by inducing another. This influenced the Hungarian neuropsychiatrist Ladislas von Meduna who in 1934 successfully treated a patient with catatonia by injecting camphor to induce seizure [2]. Camphor was soon replaced by pentylenetetrazole - however, the painful injection and associated side-effects made the practice unpopular. Thereafter, Lucio Bini and Ugo Cerletti in 1938 for the first time successfully treated a patient by electroconvulsive therapy(ECT) [3]. In early 1940s with the introduction of muscle relaxants, ECT became a very acceptable treatment until 1950 s when the practice of ECT took the backseat with the introduction of antipsychotics. However, in the last few decades there has been a revival of ECT and currently it is one of the most controversial but effective treatments in the whole of medical science. 


\section{BIOPHYSICS OF ECT}

ECT is defined to be a form of brain stimulation in which induction of a seizure occurs when an applied electrical stimulus creates an electric field with flow of current in the excitable tissue of the brain sufficient to depolarize cell membranes of neurons asynchronously [4]. The two most commonly used current waveforms in ECT practice are the sine wave and brief pulse wave forms [5]. The physiological efficiency of the brief pulse stimulus in activating brain neurons is more optimal than the sine wave because of its rapid rise and fall. Brief pulses are characterized by four stimulus parameters: pulse width, frequency, duration and peak current [6]. The 'brief' pulse is defined by a width of $0.5-2 \mathrm{~ms}$ and the ultra-brief pulse, which has been used since $1990 \mathrm{~s}$, is characterised by a width $<0.5 \mathrm{~ms}$ [7].

ECT devices differ in whether they administer the stimulus via a constant current or constant voltage. Because current is now recognized as being of greater physiological importance than voltage in ECT, constant-current devices are mostly in use. In the presence of a constant current machine, impedance i.e. resistance is a determinant of how much voltage is required for a fixed flow of electrons. Variation in impedance is caused by skull anatomy, position of electrodes, inter-electrode distance and others (like sweat, conducting gel).

\section{OVERVIEW OF THE MECHANISM OF ACTION OF ECT}

A wealth of preclinical and clinical data attests to ECT's potent effects on the CNS. Ottosson's classic research with lidocaine modified ECT seizures established the seizure as the crucial component of ECT [8]. Later, the finding that low-dose right unilateral ECT may produce suboptimal clinical outcomes confirmed that ECT seizures are not all equivalent [9]. It appears that both the anatomic site of seizure initiation and the type and intensity of the electrical stimulus affect both efficacy and cognitive effects [10]. The four main theories of ECT's mechanism of action are :

1. The monoamine neurotransmitter theory - ECT works by increasing neurotransmitter availability or changing receptor sensitivity. ECT is known to enhance dopaminergic, serotonergic, and adrenergic neurotransmission [11]. GABA and glutamate have been implicated as well [12-13].

2. The neuroendocrine theory - ECT induces a release of hypothalamic or pituitary hormones, including prolactin, thyroid stimulating hormone, adrenocorticotropic hormone, and endorphins [14]. It is theorized that the release of these hormones results in the treatment's antidepressant effect. Further evidence for this theory lies in the dysregulation of the hypothalamicpituitary-adrenal axis in melancholic depression, an abnormality that is corrected with successful ECT [15].

3. The anticonvulsant theory - ECT's efficacy is a result of the anticonvulsant nature of the treatment. Evidence for this mechanism includes the observations that seizure threshold rises (and seizure duration decreases) over a course of ECT [16]. Neuro-hormones and GABA have been postulated to mediate this anticonvulsant effect [17].

4. The neurotrophic theory- ECT may have a positive effect by inducing neurogenesis and increasing neurotrophic signalling in the brain. Animal studies have demonstrated increased neurogenesis and synaptogenesis within the rat hippocampus after electroconvulsive shock (ECS), an animal model of ECT [1819]. Neurotrophic factors, such as brain-derived neurotrophic factor, have been 
shown to be increased after ECS in animals and ECT in humans [20]. Functional neuroimaging studies have suggested that ECT paradoxically further decreases the "hypofrontality" demonstrated in depressed populations [21]. Further neuroimaging research is needed to more fully elucidate the effects of ECT on regional brain function.

\section{INDICATIONS AND EFFICACY}

In general, ECT can be considered either a primary or a secondary treatment. In recent years, efforts have been made to identify good clinical practice by creating treatment algorithms based on evidence-based medicine and expert opinion [22]. Now, we discuss the different psychiatric and non-psychiatric conditions where ECT is indicated.

\section{Depressive disorder}

ECT is the most effective treatment for major depression. It is commonly used as the standard against which other treatments are compared [4]. As early as 1940s, ECT had been found to be an extremely effective treatment for depression. When the first antidepressant medications were introduced in the 1950s, the ease of use of the antidepressants led to the decline of ECT. Re-examination of the evidence in a very comprehensive recent meta-analysis by the UK ECT Review group on depressive patients showed that real ECT was significantly more effective than simulated ECT, treatment with ECT was significantly more effective than pharmacotherapy and bilateral ECT was more effective than unipolar ECT [23]. With pharmacotherapy the maximum remission rate has been expected to be $60-70 \%$, whereas that with ECT is expected to be $80-90 \%$ [24]. ECT is a good treatment option for both unipolar and bipolar depressive patients resistant to pharmacological treatment [25]. Nevertheless, while the unipolar group show better response and clinical outcomes, the bipolar patients tend to exhibit residual manic and psychotic symptomatology [26].

Important predictors of response among patients with unipolar major depressive disorder are presence of melancholic features, acute catatonic features or delusions [27]. This response refers to acute response only as patients with melancholic features are at a greater chance of relapse thereby necessitating continuation ECT as per findings of the Consortium for Research in ECT group [28]. The predictors of poor response are depressive episodes occurring in the context of a concurrent mental or medical disease or co-morbid dysthymia or personality disorder. However, even in that group patients should not be denied the benefits of ECT if such a situation arises.

Many practitioners do not consider referral for ECT before multiple antidepressants have been tried, a process that may span many months or even years and leave the patient seriously ill, suffering, and dysfunctional, for a prolonged period [22] and consequently treatment resistant - a reason why such delay may be inadvisable [29]. There is greater agreement on use of ECT before any medication trials in situations where the patient is at the high end of the severity spectrum. Situations that compel this "primary" use of ECT are active suicidal ideation and behaviour, severe weight loss, malnutrition, dehydration from loss of appetite due to depression, with accompanying worsening of medical status; and psychosis accompanied by agitation [30]. 


\section{Mania}

ECT is an effective treatment for acute mania. Reviews have reported improvement in approximately $80 \%$ of manic patients treated with ECT [31]. It reduces the high mortality rates from exhaustion and suicide in mania [32]. ECT should be considered in mania cases that are acutely treatment refractory or require aggressive therapy for maintenance stabilization [33]. Furthermore, ECT may play a more significant role in the treatment of patients with delirious mania or in rapid-cycling manic states [6].

\section{Schizophrenia}

A lack of consensus currently exists on when to use ECT in the treatment of individuals with schizophrenia. The American Psychiatric Association's Committee on Electroconvulsive Therapy recommended the use of ECT in patients who have a history of a favorable response to ECT or who have abrupt psychotic exacerbations, catatonic schizophrenia, or schizoaffective disorder (where there is a mixture of schizophrenia and mood disorder symptoms); however, the committee recommends against ECT if "negative" symptoms of schizophrenia (e.g., withdrawal, mutism, poor self-care, flat affect) predominate [6]. The National Institute for Clinical Excellence in the United Kingdom does not recommend the general use of ECT for people with schizophrenia, although catatonia is considered an indication [34]. However, in a meta-analysis of studies evaluating the efficacy of combined ECT and antipsychotic therapy in schizophrenia, it was found that the combination might be better than antipsychotic drugs used alone in the first few weeks of treatment for schizophrenia [35]. The use of continuation ECT combined with maintenance antipsychotic medication provides better treatment outcomes than either treatment alone (including improving the patient's quality of life and functioning in the long term) [36]. The potency of combination therapy has caused some to call for a reconsideration of ECT on even a primary basis in patients with schizophrenia [37]. Some particularly impressive results have been obtained with clozapine non-responders who then received the combination of ECT and clozapine [38].

\section{Schizoaffective Disorder}

The use of ECT in patients with schizoaffective disorder is particularly relevant in the context of acute mood symptoms (i.e., depressive or manic symptoms co-occurring with psychosis or in the absence of psychosis).

\section{Other psychiatric disorders}

ECT has been tried in patients with a variety of other mental disorders. No compelling evidence supports the effectiveness of ECT in the treatment of dysthymia, anxiety disorders, substance abuse disorders, eating disorders, or personality disorders; however, the clinician should always bear in mind that a diagnostic indication for ECT may coexist with these and other psychiatric conditions.

\section{Certain medical conditions}

ECT has selective neurobiological effects that may help in the treatment of certain medical conditions. Neuroleptic malignant syndrome [39-40], refractory Parkinson's disease [41], some forms of intractable epilepsy [42], and certain endocrinopathies (hypopituitarism) have been documented to be responsive to ECT when other therapies have failed [43]. 


\section{MAINTENANCE TREATMENT WITH ECT}

Multiple psychiatric disorders, including major depressive disorder, psychotic depression, bipolar disorder, schizoaffective disorder and schizophrenia respond to maintenance ECT [44]. Use of maintenance ECT in the geriatric population is also well documented [45]. Criteria for continuation ECT should include all of the following: a history of recurrent illness that is acutely responsive to ECT; limited medical comorbidities that increase risk for additional ECT or anesthesia; ineffectiveness or intolerance to prophylaxis with pharmacotherapy (or patient preference for ECT) and ability and willingness to comply with logistical arrangements (because continuation treatments are almost always performed on an outpatient basis) [6]. Although an optimal protocol for timing of treatments still remains to be determined, a typical arrangement would involve weekly ECT for 4 weeks, then incremental increases in the interval between ECT treatments to once a month to over the next few months [46].

\section{ECT USE IN SPECIAL POPULATIONS}

\section{Children and Adolescents}

The use of ECT is rare in children and adolescents and information on efficacy and adverse effects is extremely limited. However, available data suggest that diagnostic indications for the use of ECT in children and adolescents are the same as those for adults [48]. American Psychiatric Association (2001) recommends that prior to using ECT in an adolescent younger than age 18 years, a physician should seek a second opinion from a psychiatrist who is experienced in treating minors [6]. Two such consultations are recommended for children younger than age 12 years. Guidelines for use of ECT in adolescents have been developed by the American Academy of Child and Adolescent Psychiatry [48].

\section{ECT in the Elderly}

In a Cochrane review reported that the randomized evidence on the efficacy and safety of ECT in elderly depressed patients is sparse [49]. In a review of the larger research literature (including non-randomized studies) strongly supported the efficacy of ECT in depressed elderly patients than in younger patients [50]. The use of ECT in elderly patients is generally safe, but it does present some challenges [51].These complications may be due to the fact that older patients have more medical illnesses, less cognitive reserve, more susceptible to medication side-effects and the seizure threshold is usually higher for them, often requiring a higher electrical stimulus intensity to produce an adequate seizure [6].

\section{Pregnancy}

Pregnancy is not a contraindication to ECT, although an obstetrical consultation is recommended for every patient who is pregnant, and noninvasive fetal monitoring should be performed when indicated. The pharmacological agents used at the time of ECT have no known teratogenic or other adverse effects. However, during the last trimester, a greater risk of gastric reflux is possible due to the mass effect produced by the growing fetus [52]. 


\section{ECT PROCEDURE}

Before beginning ECT risk benefit analysis should be done keeping the above indications in mind and also the possible adverse effects and contraindications to be discussed later. After a proper informed consent from the patient or the legal guardian an anaesthesiologist consultation should be sought for pre-anaesthetic check-up and thereafter the procedure should be started.

\section{Pre-ECT Medical Evaluation}

The process of medical optimization prior to ECT begins with taking a full general medical history during the ECT consultation. The cardiovascular, pulmonary, and central nervous systems are the organ systems of most relevance for which specialty consultations may be considered [53].The pre-ECT laboratory evaluation varies among institutions but typically includes an electro-cardiogram, complete blood count, a chemistry panel, and a pregnancy test for women of child bearing age. Pre-ECT $\mathrm{X}$-rays (chest $\mathrm{X}$-ray, spine films) and brain imaging are no longer routinely ordered. However, skeletal evaluation for risk of fractures during the procedure is done. Brain imaging is recommended when a questionable neurocognitive history, focal finding on neurological or fundoscopic examination are present. Dental evaluationto rule out loose teeth should be performed prior to ECT.

Decisions about which medication to continue or withhold during the course of ECT are made judiciously. Whereas in the past most psychotropic medications were discontinued during ECT, current practice is much more permissive, particularly with regard to antidepressants which may augment the acute ECT response [54]. Medications with anticonvulsant properties are generally decreased or discontinued [55]. Commonly, if a patient is taking antihypertensive, other cardiac, or gastroesophageal reflux medications, these are given on the morning of the procedure; otherwise, the patient is instructed not to eat or drink for 8 hours.

\section{Physiological Monitoring During ECT}

ECT is performed under general anaesthesia with muscle paralysis; the standards for basic anaesthesia monitoring must be observed. Vital signs (heart rate, blood pressure, temperature), blood oxygen saturation, end-tidal carbon dioxide levels, ECG, EEG, are monitored during ECT. Initial activation of central parasympathetic centres by the electrical stimulus will result in bradycardia in up to $30 \%$ of patients, and short periods of asystole are not uncommon. Subsequent activation of the sympathetic nervous system during seizure activity will result in tachycardia in most patients. While these dysrhythmias are almost always benign and self-limited, close observation or signs of ischemia in patients at risk is warranted. The use of pulse oxymetry is also mandatory. Other desirable are electromyographic (EMG) monitoring to indicate the motor component of the seizure during ECT [30].

\section{Anaesthesia during ECT}

The goal of anesthesia during ECT is to induce in the patient a brief period of amnesia covering the period of the electrical stimulation and the action of the muscle-relaxing agent. However, the level of anaesthesia should not be so deep as to overly suppress the seizure activity. Methohexital used in the dose of $0.75-1.0 \mathrm{mg} / \mathrm{kg}$ of body weight is most commonly used and has the advantages of rapid action, low cardiac toxicity, and a low incidence of post-anesthesia confusion [56]. In a recent systematic review, methohexital was shown to be superior to other anesthetics with 
regard to motor seizure duration [57]. Other anaesthetics like propofol and etomidate can be used as as alternatives. Succinylcholine is the preferred relaxant agent administered intravenously by either bolus or drip (the usual dose is $0.75-1.25 \mathrm{mg} / \mathrm{kg}$ ). Apart from this, anticholinergics like atropine or glycopyrrolate can be of use.

\section{Choice of Electrode Placement}

In contemporary ECT practice, three electrode placements are commonly used: right unilateral, bilateral, and bifrontal [58]. Bilateral and bifrontal electrode placements may have slightly greater overall efficacy and speed of response, but may cause considerably more retrograde amnesia than right unilateral electrode placement [6].There is large individual variability among patients, both in drug response and in cognitive adverse effects. One common treatment strategy is to start a course with right unilateral ECT; if the patient is not responding after three to six treatments, despite adjustments in stimulus dosing, switch to bilateral placement may be made [59]. In general, the more severely ill (both psychiatrically and medically)a patient is, the more likely he or she will be started with bilateral electrode placement. With right unilateral electrode placement, a newer type of electrical stimulus, ultrabrief pulse, shows promise for further reducing the cognitive adverse effects of ECT [60]

\section{Frequency of Treatment}

In some centres ECT is typically administered three times a week whereas in other countries, a twice-a-week schedule is followed. Recent evidence suggests that outcomes are comparable between the two schedules, and that a three times-per-week schedule may produce results slightly more quickly but cause somewhat more cognitive impairment [61].

\section{ADVERSE EFFECTS OF ECT}

According to the American Psychiatric Association (2001), ECT has no absolute contraindications. However, some conditions pose a relatively high risk like space-occupying intracerebral lesions (except small, slow-growing tumors without edema or other mass effect), other conditions causing increased intracranial pressure, recent myocardial infarction with substantially compromised cardiac function, recent intracerebral hemorrhage, unstable vascular aneurysms or malformations, and pheochromocytoma [6]. The overall mortality rate from ECT in a general population of patients is extremely low, estimated at $2-10$ per 100,000 patients $(0.0001 \%)$ [62]. This is roughly the same ratio as from the induction of brief general anesthesia itself. Though there is almost no chance of mortality with ECT yet there are some adverse effects. Headache, muscle soreness and jaw pain are amongst the most common side effects and usually requires only symptomatic treatment. Cognitive impairment includes postictal disorientation, interictal confusion, and amnesia (anterograde and retrograde memory disturbances). While cardiovascular effects constitute the smallest portion, they are associated with maximum mortality and serious morbidity. There can be transient ischemic changes in susceptible individuals. Depending upon sympathetic or parasympathetic stimulation there can be tachycardia, bradycardia, arrythymias or premature ventricular beats. Use of pre-anaesthetic medication has significantly lowered such incidences [63]. 


\section{CONTROVERSY REGARDING ECT}

Controversy has been hand in glove with ECT since the very beginning. In the early 1940's it was hailed as a magic wand while by late 1970's antipsychiatry lobby accused this as inhuman, excrutiatingly painful and baseless therapy. Once again as human right agenda takes center stage, complete ban on this procedure has been demanded. In a review of biopsychosocial perspective of electroconvulsive therapy, Nancy Payne and Joan Prudic highlights the major reasons for misinformation about ECT in general public. According to them, media, depiction in films, coalition lobbying for anti-ECT legislation and the internet are the major avenues responsible [64]. The authors observed that no education campaign regarding ECT, aiming at both public and health community has ever been taken. Anti -psychiatry campaign continues to oppose ECT at all levels, questioning its unknown mechanisms of action. According to them, only way ECT works is by behavioural changes in patients which occurs as an active attempt to further avoid the horrifying therapy. Redundant examples of patient's horrifying ordeals from pre-MECT period are still cited and used to garner support. They claim ECT causes brain damage leading to decreased intelligence and permanent memory loss. Apart from this, the fact that these are given without taking patient's consent on certain occasions, is a blatant violation of human rights [65].

According to the mental health care bill 2013, indirect ECT and ECT to minors has been completely abolished, while ECT's given on pretext of emergency management will be scrutinizable [66]. It was perhaps the addendum of the above mentioned factors that led the government to propose the stringent measure against the use of ECT in mental health care bill, a move that has been described as politically appeasing rather than being scientifically sound. It has been argued that since there has been no clear cut studies regarding the adverse effects in minors and ECT is the treatment of choice in catatonic patients, this may lead to hindrances in emergency management of such patients [67].Similarly, banning indirect ECT would take away a highly effective yet cheap option of treatment, affecting a large number of patients [68]. Indian Association of Private Psychiatrists supported modified ECT as the preferred method, they however highlighted issues where unmodified ECT could be considered, mainly in developing countries where resources are constrained and burden excessive. Based on previous studies, consensus among authors and participating members recommendations of using unmodified ECT, it have been spelled out, with a caution over the use of unmodified ECT solely for convenience [69]. Despite this clear statement, it was chosen to overlook this in favour of aesthetically accepted treatments.

\section{CONCLUSIONS}

Over the past 75 years, ECT has continued to survive despite some groundbreaking changes in pharmacological management of psychiatric disorders. It still remains treatment of choice for certain indications. Over the years, there has been improvement in methods of giving ECT, leading to improved efficacy and lesser adverse effects. Further advances are made where current is introduced through magnetic fields and newer approaches like transcranial magnetic stimulation are coming into foray. The debate on ECT being an effective or inhuman treatment is likely to continue. 


\section{REFERENCES}

1. Berrios GE. The scientific origins of electroconvulsive therapy: a conceptual history. Hist Psychiatry 1997;8:105-19.

2. Fink M. Meduna and the origins of convulsive therapy. Am J Psychiatry 1984;141:1034-41.

3. Faedda GL, Becker I, Baroni A, Tondo L, Aspland E, Koukopoulos A. The origins of electroconvulsive therapy: Prof. Bini's first report on ECT. J Affect Disord 2010;120:12-5.

4. Sadock BJ, Sadock VA, Ruiz P, editors. Kaplan and Sadock's Comprehensive Textbook of Psychiatry. 9th ed. Lippincott Williams \& Wilkins; 2009.

5. Sackeim HA, Long J, Luber B, Moeller JR, Prohovnik I, Devanand DP, et al. Physical properties and quantification of the ECT stimulus: Basic principles. Convuls Ther 1994; 10:93-123.

6. Beyer JL, Weiner RD, Krystal A. Clinical Manual of Electroconvulsive Therapy. American Psychiatric Pub; 2010.

7. Sackeim HA, Prudic J, Nobler MS, Fitzsimons L, Lisanby SH, Payne N, et al. Effects of pulse width and electrode placement on the efficacy and cognitive effects of electroconvulsive therapy. Brain Stimulat. 2008;1:71-83.

8. Cronholm B, Ottosson JO. Experimental studies of the therapeutic action of electroconvulsive therapy in endogenous depression. The role of the electrical stimulation and of the seizure studied by variation of stimulus intensity and modification by lidocaine of seizure discharge. Acta Psychiatr Scand 1960;35:69-101.

9. Sackeim HA, Prudic J, Devanand DP, Kiersky JE, Fitzsimons L, Moody BJ, et al. Effects of stimulus intensity and electrode placement on the efficacy and cognitive effects of electroconvulsive therapy. N Engl J Med 1993;328:839-46.

10. Sackeim HA, Prudic J, Devanand DP, Nobler MS, Lisanby SH, Peyser S, et al. A prospective, randomized, double-blind comparison of bilateral and right unilateral electroconvulsive therapy at different stimulus intensities. Arch Gen Psychiatry 2000;57:425-34.

11. Heninger GR, Delgado PL, Charney DS. The revised monoamine theory of depression: a modulatory role for monoamines, based on new findings from monoamine depletion experiments in humans. Pharmacopsychiatry 1996;29:2-11.

12. Pfleiderer B, Michael N, Erfurth A, Ohrmann P, Hohmann U, Wolgast $M$, et al. Effective electroconvulsive therapy reverses glutamate/glutamine deficit in the left anterior cingulum of unipolar depressed patients. Psychiatry Res 2003;122:185-92.

13. Esel E, Kose K, Hacimusalar Y, Ozsoy S, Kula M, Candan Z, et al. The effects of electroconvulsive therapy on GABAergic function in major depressive patients. J ECT 2008;24:224-8.

14. Kamil R, Joffe RT. Neuroendocrine testing in electroconvulsive therapy. Psychiatr Clin North Am 1991;14:961-70.

15. Melancholia: The Diagnosis, Pathophysiology and Treatment of Depressive Illness. Cambridge University Press; 2006.

16. Sackeim HA. The anticonvulsant hypothesis of the mechanisms of action of ECT: current status. J ECT 1999;15:5-26.

17. Holaday JW, Tortella FC, Long JB, Belenky GL, Hitzemann RJ. Endogenous opioids and their receptors. Evidence for involvement in the postictal effects of electroconvulsive shock. Ann N Y Acad Sci 1986;462:124-39.

18. Chen F, Madsen TM, Wegener G, Nyengaard JR. Repeated electroconvulsive seizures increase the total number of synapses in adult male rat hippocampus. Eur Neuropsychopharmacol 2009;19(5):329-38.

19. Madsen TM, Treschow A, Bengzon J, Bolwig TG, Lindvall O, Tingström A. Increased neurogenesis in a model of electroconvulsive therapy. Biol Psychiatry 2000;47:1043-9.

20. Piccinni A, Del Debbio A, Medda P, Bianchi C, Roncaglia I, Veltri A, et al. Plasma BrainDerived Neurotrophic Factor in treatment-resistant depressed patients receiving electroconvulsive therapy. Eur. Neuropsychopharmacol. J. Eur. Coll. Neuropsychopharmacol. 2009;19(5):349-55. 
21. Nobler MS, Oquendo MA, Kegeles LS, Malone KM, Campbell CC, Sackeim HA, et al. Decreased regional brain metabolism after ect. Am J Psychiatry 2001;158:305-8.

22. Beale MD, Kellner CH. ECT in treatment algorithms: no need to save the best for last. J Ect 2000;16:1-2.

23. Efficacy and safety of electroconvulsive therapy in depressive disorders: a systematic review and meta-analysis. Lancet 2000;361:799-808.

24. Practice guideline for the treatment of patients with major depressive disorder (revision). American Psychiatric Association. Am J Psychiatry 2000;157:1-45.

25. Dierckx B, Heijnen WT, van den Broek WW, Birkenhäger TK. Efficacy of electroconvulsive therapy in bipolar versus unipolar major depression: a meta-analysis. Bipolar Disord 2012; 14:146-50.

26. Medda P, Perugi G, Zanello S, Ciuffa M, Cassano GB. Response to ECT in bipolar I, bipolar II and unipolar depression. J Affect Disord 2009;118:55-9.

27. Fink M. Electroshock: restoring the mind. Oxford University Press, Incorporated; 1999.

28. Fink M, Rush AJ, Knapp R, Rasmussen K, Mueller M, Rummans TA, et al. DSM melancholic features are unreliable predictors of ECT response: a CORE publication. J ECT 2007; 23:139-46.

29. Perugi G, Medda P, Zanello S, Toni C, Cassano GB. Episode length and mixed features as predictors of ECT nonresponse in patients with medication-resistant major depression. Brain Stimulat 2012;5:18-24.

30. Kellner $\mathrm{CH}$, Greenberg RM, Murrough JW, Bryson EO, Briggs MC, Pasculli RM. ECT in treatment-resistant depression. Am J Psychiatry 2012;169:1238-44.

31. Mukherjee S, Sackeim HA, Schnur DB. Electroconvulsive therapy of acute manic episodes: a review of 50 years' experience. Am J Psychiatry 1994;151:169-76.

32. Fink M. ECT in therapy-resistant mania: does it have a place? Bipolar Disord 2006;8:3079.

33. Nascimento AL, Appolinario JC, Segenreich D, Cavalcanti MT, Brasil MAA. Maintenance electroconvulsive therapy for recurrent refractory mania. Bipolar Disord 2006;8:301-3.

34. NICE. TA59 Electroconvulsive therapy (ECT): guidance [Internet]. [cited 2013 Apr 27]. Available from: http://publications.nice.org.uk/guidance-on-the-use-of-electroconvulsivetherapy-ta59

35. Painuly N, Chakrabarti S. Combined use of electroconvulsive therapy and antipsychotics in schizophrenia: the Indian evidence. A review and a meta-analysis. J ECT 2006;22:59-66.

36. Chanpattana W, Andrade C. ECT for treatment-resistant schizophrenia: a response from the far East to the UK. NICE report. J ECT 2006;22:4-12.

37. Hertzman M. ECT and neuroleptics as primary treatment for schizophrenia. Biol Psychiatry 1992;31:217-20.

38. Kho KH, Blansjaar BA, de Vries S, Babuskova D, Zwinderman AH, Linszen DH. Electroconvulsive therapy for the treatment of clozapine nonresponders suffering from schizophrenia--an open label study. Eur Arch Psychiatry Clin Neurosci 2004;254:372-9.

39. Bhanushali MJ, Tuite PJ. The evaluation and management of patients with neuroleptic malignant syndrome. Neurol Clin 2004;22:389-411.

40. Ghaziuddin N, Alkhouri I, Champine D, Quinlan P, Fluent T, Ghaziuddin M. ECT treatment of malignant catatonia/NMS in an adolescent: a useful lesson in delayed diagnosis and treatment. J ECT 2002;18:95-8.

41. Fregni F, Simon DK, Wu A, Pascual-Leone A. Non-invasive brain stimulation for Parkinson's disease: a systematic review and meta-analysis of the literature. J Neurol Neurosurg Psychiatry 2005;76:1614-23.

42. Lisanby SH, Bazil CW, Resor SR, Nobler MS, Finck DA, Sackeim HA. ECT in the treatment of status epilepticus. J ECT 2001;17:210-5.

43. Pitts FN Jr, Patterson CW. Electroconvulsive therapy for iatrogenic hypothalamichypopituitarism (CRF-ACTH type). Am J Psychiatry 1979;136:1074-7.

44. Birkenhäger TK, van den Broek WW, Mulder PGH, de Lely A. One-year outcome of psychotic depression after successful electroconvulsive therapy. J ECT 2005;21:221-6. 
45. Thienhaus OJ, Margletta S, Bennett JA. A study of the clinical efficacy of maintenance ECT. J Clin Psychiatry 1990;51:141-4.

46. Clarke TB, Coffey CE, Hoffman GW Jr, Weiner RD. Continuation Therapy for Depression Using Outpatient Electroconvulsive Therapy. Convuls Ther 1989;5:330-7.

47. Bertagnoli MW, Borchardt CM. A review of ECT for children and adolescents. J Am Acad Child Adolesc Psychiatry 1990;29:302-7.

48. Ghaziuddin N, Kutcher SP, Knapp P, Bernet W, Arnold V, Beitchman J, et al. Practice parameter for use of electroconvulsive therapy with adolescents. J Am Acad Child Adolesc Psychiatry 2004;43:1521-39.

49. Van der Wurff FB, Stek ML, Hoogendijk WL, Beekman AT. Electroconvulsive therapy for the depressed elderly. Cochrane Database Syst. Rev. Online. 2003;2:CD003593.

50. Van der Wurff FB, Stek ML, Hoogendijk WJG, Beekman ATF. The efficacy and safety of ECT in depressed older adults: a literature review. Int J Geriatr Psychiatry 2003;18:894-904.

51. Greenberg L, Fink M. The use of electroconvulsive therapy in geriatric patients. Clin Geriatr Med 1992;8:349-54.

52. Anderson EL, Reti IM. ECT in pregnancy: a review of the literature from 1941 to 2007. Psychosom Med 2009;71:235-42.

53. Tess AV, Smetana GW. Medical evaluation of patients undergoing electroconvulsive therapy. N Engl J Med 2009;360:1437-44.

54. Sackeim HA, Dillingham EM, Prudic J, Cooper T, McCall WV, Rosenquist $P$, et al. Effect of concomitant pharmacotherapy on electroconvulsive therapy outcomes: short-term efficacy and adverse effects. Arch Gen Psychiatry 2009;66:729-37.

55. Sienaert $\mathrm{P}$, Peuskens J. Anticonvulsants during electroconvulsive therapy: review and recommendations. J Ect 2007;23:120-3.

56. Mokriski BK, Nagle SE, Papuchis GC, Cohen SM, Waxman GJ. Electroconvulsive therapyinduced cardiac arrhythmias during anesthesia with methohexital, thiamylal, or thiopental sodium. J Clin Anesth 1992;4:208-12.

57. Hooten WM, Rasmussen KG Jr. Effects of general anesthetic agents in adults receiving electroconvulsive therapy: a systematic review. J ECT 2008;24:208-23.

58. Kellner $\mathrm{CH}$, Tobias KG, Wiegand J. Electrode placement in electroconvulsive therapy (ECT): A review of the literature. J ECT 2010;26:175-80.

59. Abrams R. Electroconvulsive Therapy. 4th ed. Oxford University Press, USA; 2002.

60. Sienaert P, Vansteelandt K, Demyttenaere K, Peuskens J. Randomized comparison of ultrabrief bifrontal and unilateral electroconvulsive therapy for major depression: cognitive side-effects. J Affect Disord 2010;122:60-7.

61. Charlson F, Siskind D, Doi SAR, McCallum E, Broome A, Lie DC. ECT efficacy and treatment course: a systematic review and meta-analysis of twice vs thrice weekly schedules. J Affect Disord 2012;138:1-8.

62. Shiwach RS, Reid WH, Carmody TJ. An analysis of reported deaths following electroconvulsive therapy in Texas, 1993-1998. Psychiatr Serv Wash Dc 2001;52:1095-7.

63. Mankad MV, Weiner RD. Adverse Effects. In: Mankad MV, Beyer JL, Weiner RD, Krystal AD. Clinical Manual Of ECT Therapy. $1^{\text {st }}$ Ed. Washington DC. APA press;2010. pp139-45

64. Payne NA, Prudic J. Electroconvulsive therapy: Part II. A biopsychosocial perspective. J Psychiatric Pract 2009b;15:369-90

Acknowledgements - Nil.

Conflict of Interest - Nil.

Funding - Nil. 